\title{
Movilidad social de familias gallegas en Buenos Aires pertenecientes a la última corriente migratoria: estrategias y trayectorias
}

\author{
Laura Oso \\ Universidade da Coruña. Facultade de Socioloxia. ESOMI \\ laura.oso@udc.es \\ ORCID: 0000-0003-1532-6196 \\ Pablo Dalle \\ Paula Boniolo \\ CONICET / Universidad de Buenos Aires. Instituto de Investigaciones Gino Germani \\ pablodalle80@hotmail.com \\ ORCID: 0000-0002-4367-8562 \\ pboniolo@sociales.uba.ar \\ ORCID: 0000-0002-7756-095X
}

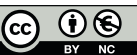

Recepción: 17-04-2018

Aceptación: 19-06-2018

Publicación: 18-12-2018

\section{Resumen}

La migración gallega constituyó el grupo etnicoregional más numeroso de la inmigración de ultramar a Argentina, a tal punto que Buenos Aires fue considerada «capital de la quinta provincia gallega». Si bien existe una amplia producción científica sobre esta migración, la movilidad social de este grupo etnicoregional ha sido menos abordada. El objetivo del artículo es analizar pautas y estrategias de movilidad social (intra e intergeneracionales) desplegadas por familias migrantes gallegas de origen de clase popular, pertenecientes a la última corriente migratoria que arribó a Argentina entre 1940 y 1960, identificando las oportunidades y los obstáculos que encontraron las familias en sus trayectorias de clase. Para abordar este objetivo, se utiliza una perspectiva teórica que propone articular las estrategias de movilidad espacial y movilidad social analizando, con un enfoque de género e intergeneracional, la posición de clase de varios miembros de la familia. Dicho enfoque pone de relieve la importancia de considerar múltiples factores, más allá de la educación y la ocupación, en el análisis de las trayectorias de clase. El diseño metodológico combina el análisis estadístico de encuestas sobre movilidad social intergeneracional y 34 entrevistas biográficas llevadas a cabo en Buenos Aires con miembros de familias migrantes. El estudio da cuenta de cómo un entramado complejo de estrategias articuladas, influidas por un

* Este artículo ha sido elaborado en el marco del proyecto INCASI, financiado por The European Union's Horizon 2020 Research and Innovation Programme, Marie Skłodowska-Curie (GA No 691004). El proyecto está coordinado por el Dr. Pedro López-Roldán (Universitat Autònoma de Barcelona). El artículo refleja solo el punto de vista de los autores, y la agencia no es responsable del uso que se haga de la información que contiene. 
proyecto migratorio de asentamiento, contribuye a comprender mejor las trayectorias de clase de las familias de origen gallego en Buenos Aires: procesos de movilidad social ascendente de larga y corta distancia escalonados, basados en el encadenamiento de esfuerzos y acumulación de recursos entre generaciones.

Palabras clave: movilidad social; migrantes gallegos; Buenos Aires; estrategias familiares; trayectorias de clase; género; entrevistas biográficas

Abstract. The social mobility of Galician families in Buenos Aires belonging to the latest migratory flow: Strategies and trajectories

Galician migration constituted the largest ethnic-regional group of overseas immigrants to Argentina to such an extent that Buenos Aires was popularly known as Galicia's 'fifth province'. Despite the considerable scientific production addressing this migratory issue, only scant attention has been given to the social mobility of this ethnic-regional group. The aim of this article is to analyse the intra- and intergenerational social mobility patterns and strategies deployed by Galician migrant families of working class origin which comprised the last migratory flow that arrived in Argentina between 1940 and 1960 and to identify the opportunities and obstacles families encountered in their class trajectories. The research is based on a theoretical perspective which considers the articulation between spatial and social mobility strategies through a gender and intergenerational-based approach to the analysis of the class status of several family members. This approach highlights the need to consider multiple factors beyond education and occupation when analysing social mobility strategies. A mixed methodology combining both quantitative and qualitative techniques was used and a statistical analysis was performed of intergenerational social mobility surveys and 34 life story interviews conducted with members of migrant families in Buenos Aires. The study reveals how a complex network of articulated strategies, influenced by a migratory project based on the desire to settle, provides clearer insight into the class trajectories of families of Galician origin in Buenos Aires, which involved staggered, short-term and long-term upward social mobility processes based on sustained inter-generational effort and resource accumulation.

Keywords: social mobility; Galician migrants; Buenos Aires; family strategies; class trajectories; gender; life story interviews

\section{Sumario}

\section{Introducción}

2. Analizar la movilidad social en su articulación con la movilidad espacial

3. Datos y métodos

4. Movilidad social de familias de origen español
5. Proyectos, estrategias y trayectorias de movilidad de las familias migrantes gallegas

6. Conclusiones

Referencias bibliográficas

\section{Introducción}

Más de diez mil kilómetros separan Buenos Aires de los puertos de Vigo y A Coruña, sin embargo, cientos de miles de familias migraron desde sus aldeas natales persiguiendo el sueño del progreso social que prometía "América» y que 
Galicia, labriega y mariñeira, pobre y estancada, le cerraba a los hijos/as de su tierra. Primero, durante las últimas décadas del siglo XIX, el destino preferido para dicha aventura había sido Cuba, todavía bajo dominio español, pero ya desde comienzos del siglo Xx la ruta cambió de dirección hacia el profundo sur. Buenos Aires fue, en las primeras décadas del siglo XX, la ciudad con mayor cantidad de gallegos en el mundo, y se la consideró «la quinta provincia gallega». El mayor volumen de migración correspondió a la primera oleada migratoria de ultramar, en la que 1.000.000 de gallegos llegaron a Argentina entre 1857 y 1930 . Después de la segunda guerra, se reanudó la corriente migratoria y fueron 110.288 personas hacia 1962 . En esta segunda corriente, aunque continuó el predominio masculino, se incrementó notablemente la participación femenina debido a un amplio movimiento de reagrupamiento familiar (Farías, 2016).

La gran mayoría de los migrantes gallegos trabajaban en su tierra de origen como labriegos en pequeños minifundios de autosubsistencia o mariñeiros. En general, tenían pocos estudios formales, aunque poseían cierto nivel de formación (Farías, 2016). Buena parte de los gallegos se asentó en la Ciudad de Buenos Aires y los partidos de su periferia (Farías, 2016; Lojo et. al, 2008; Núñez Seixas, 2007; Moya, 2004). Se calcula que el $70 \%$ de los descendientes de españoles en la ciudad de Buenos Aires y el Gran Buenos Aires son de origen gallego, y constituyen el grupo etnicoregional más numeroso de la inmigración de ultramar a Argentina (Pérez-Prado, 2007). Esta migración ha suscitado el interés académico a un lado y otro del Atlántico; si bien la aproximación a esta problemática de investigación fue fundamentalmente desde un enfoque historiográfico, en el que destacan los trabajos que abordan el período comprendido entre la emancipación colonial y la organización del Estado nación (Cristóforis, 2010), la primera corriente masiva (1857-1936) de migraciones de ultramar (Villares y Fernández, 1996; Núñez Seixas, 2007; Orden, 2005); y son menos frecuentes, tal y como pone de relieve Farías (2016), los estudios sobre la segunda corriente (Farías, 2016; Vázquez González, 2011; Soutelo Vázquez, 2006; Cristóforis, 2007). Además, salvo algunos trabajos, como el de Núñez Seixas y Farías (2012) que llevan a cabo un análisis de fuentes autobiográficas, migración no ha sido estudiada desde la problemática de la movilidad social ${ }^{1}$, siendo escaso el enfoque de género (Cagiao Vila, 1997). Otros estudios abordan la problemática de la movilidad social, pero considerando la migración española en general y no específicamente la gallega (Moya, 2004; Orden, 2005). Este artículo pretende contribuir a la producción científica analizando las pautas y estrategias de movilidad social (intra e intergeneracionales) desplegadas por familias migrantes gallegas, de origen de clase popular, pertenecientes a la última corriente migratoria que arribó a Argentina entre 1940 y 1960, identificando las oportunidades y los obstáculos que encontraron estas familias en sus trayectorias de clase.

1. En los últimos años se defendieron tres tesis doctorales sobre la movilidad social de los migrantes argentinos en España (Jimenez Zunino, 2011; Laíz Moreira, 2014) y retornados (Cassain, 2018). 
En segundo lugar, el artículo busca contribuir a los debates sobre la relación entre movilidad espacial y movilidad social. A pesar del importante avance que han tenido, en el ámbito de la sociología, los estudios sobre movilidad social, gracias al uso de técnicas estadísticas sofisticadas de análisis - tablas de movilidad social, path analysis, análisis long-lineal- (Cuin, 1993), son escasos los trabajos que han relacionado la temática de la movilidad social con la movilidad geográfica. La mayoría de las investigaciones se han centrado en analizar, desde un enfoque cuantitativo, las trayectorias de movilidad ocupacional y educativa, intra e intergeneracionales, de la población migrante en los contextos de acogida de la inmigración (Chiswick et al, 2005, entre otros). Desde un enfoque cualitativo, destaca la línea de investigación, iniciada por Bertaux y Thompson (1997), que aborda la movilidad social a través de historias de familia; si bien esta aproximación aplicada al estudio de la migración internacional ha estado menos desarrollada. Por lo general, la producción científica ha dejado en un papel secundario el análisis de otros determinantes (más allá de la educación y la ocupación) que operan para entender la especificidad de las trayectorias de movilidad social de la población migrante, tales como, por ejemplo, las inversiones económicas que se realizan en el país de origen (remesas, compra de propiedades, etcétera), la presencia del capital social étnico, las estrategias de movilidad espacial (viajes de ida y vuelta) (Oso y Suárez-Grimalt, 2017).

Este artículo pretende contribuir en este sentido, abordando la movilidad social en un contexto de migración internacional desde una perspectiva que articula el análisis de la movilidad espacial y social. Este enfoque implica analizar la posición de clase de varios miembros de la familia, poniendo de relieve la importancia de considerar múltiples factores, más allá de la educación y la ocupación, en el análisis de las estrategias de movilidad social: estrategias empresariales y patrimoniales, matrimoniales, inversión en capital social y estrategias migratorias. Por otro lado, el estudio entrecruza técnicas cuantitativas y cualitativas: el análisis estadístico de encuestas sobre movilidad social intergeneracional y entrevistas biográficas a familias migrantes.

El texto aborda esta problemática de investigación desde una mirada comparativa. En primer lugar, a través del análisis cuantitativo se describe la inserción en la estructura de clases de los migrantes españoles y sus hijos/as con relación a los nativos del AMBA, otros grupos migrantes y sus descendientes, comparando igualmente las trayectorias de clase entre la primera corriente migratoria (1870-1930) y la segunda (1940-1960).

En segundo lugar, se utilizan datos procedentes de otros trabajos para contextualizar la especificidad de los proyectos migratorios y de las modalidades de inserción laboral, incluidas las estrategias de inversión económica, de los gallegos que migraron a Argentina (1940 y 1960), en comparación con los que lo hicieron a Europa en los años 60-70.

Por último, sobre la base del estudio cualitativo se profundiza en la comparación intergeneracional con un enfoque transnacional. En efecto, las biografías familiares permiten profundizar en cómo las diferentes generaciones entrelazan 
las estrategias familiares para alcanzar logros o enfrentar obstáculos en relación con los condicionamientos de la clase social de origen y del contexto sociohistórico. Así, podemos comparar la estrategia de movilidad social y geográfica de los abuelos que migraron a Buenos Aires y cruzarla con la de sus hijos/as y nietos/as, algunos de los cuales atraviesan también el Atlántico, en sentido inverso, rumbo a Galicia.

El artículo presenta, en primer lugar, el enfoque teórico que aborda la articulación entre la movilidad espacial y social y el diseño metodológico. En segundo lugar, a través del análisis estadístico, describe las pautas de movilidad social intergeneracional de familias de origen español, de las cuales alrededor del 70\% — - según las estimaciones citadas - constituyen familias gallegas. Finalmente, se reconstruyen las estrategias de movilidad social desplegadas por las familias analizadas. El artículo concluye con reflexiones sobre las estrategias y trayectorias de movilidad social de los gallegos en Buenos Aires.

\section{Analizar la movilidad social en su articulación con la movilidad espacial}

El enfoque teórico que aborda la articulación entre movilidad geográfica y social (Oso, dir. 2015; Oso, Sáiz-López, Cortés, 2017; Oso y Suárez Grimalt, 2017) tiene en cuenta, en primer lugar, la posición del individuo en el ciclo migratorio: desde su inicio, con la toma de decisión de la migración y los primeros pasos en la inserción a la sociedad de acogida, hasta un estadio avanzado. En segundo lugar, distingue entre: a) los proyectos de movilidad social imaginarios de los migrantes, es decir, los sueños y expectativas de futuro, que están directamente relacionados con los proyectos migratorios; b) las estrategias que se ponen en marcha para lograr dichos sueños, nos referimos a las elecciones del actor social ante el dilema de opciones varias, y c) las trayectorias de clase vividas, o conjunto de posiciones sociales vitales que ocupa el individuo en la jerarquía social. En tercer lugar, esta aproximación tiene en cuenta que la movilidad social no es siempre individual, sino también familiar y/o colectiva, de manera que pueden surgir contradicciones entre los intereses divergentes de los actores sociales: la movilidad ascendente para unos puede conllevar un descenso social para otros; el sacrificio de algunos miembros del hogar puede traducirse en un ascenso de estatus para el resto. Asimismo, esta propuesta analiza la movilidad social considerando diversos miembros de las familias migrantes, no solo padres e hijos/as varones, y incorpora la dimensión del análisis de género al estudio de la articulación entre la movilidad espacial y social. Y saca a la luz que la movilidad social, en un contexto migratorio, debe considerar no solo el espacio social de acogida, sino también de origen.

Por último, integramos al análisis la influencia que tiene, en la configuración de las trayectorias de movilidad social, la articulación entre el encadenamiento de estrategias, por parte de las familias, para apropiarse de oportunidades o abrirse camino en condiciones adversas y el carácter más o menos abierto de la estructura social (Dalle, 2016). En efecto, las biografías de las familias 
gallegas muestran la influencia de los cambios sociohistóricos de ambos países, y permiten reconstruir el contexto de oportunidades argentino desde su pujante expansión en la primera mitad del siglo XX hasta la crisis de 2001, cuando los descendientes de gallegos deciden hacer uso de su doble ciudadanía y migrar hacia España, como lo hicieron en sentido inverso sus abuelos décadas atrás.

Por último, el concepto de estrategia utilizado no implica la realización de proyectos autoconscientes por parte de los agentes, sino que el habitus orienta objetivamente a las prácticas identificando oportunidades y restricciones; la adecuación de «lo probable» a «lo posible» no implica descartar la capacidad de agencia de los agentes, dispuestos a improvisar para modificar sus condiciones objetivas (Bourdieu y Wacquant, 1986).

\section{Datos y métodos}

El estudio utilizó una metodología mixta. Primero, realiza un análisis estadístico descriptivo de cuatro encuestas probabilísticas del Área Metropolitana de Buenos Aires de 1961, 2005, 2010 y 2015. La encuesta de 1961 fue dirigida por Germani, Instituto de Sociología; las de 2005 y 2010, por Jorrat, y la de 2015, por Sautu, Dalle, Boniolo y Elbert, en el Instituto de Investigaciones Gino Germani. Dichas encuestas permiten estudiar pautas de movilidad social intergeneracional contando con información sobre la posición ocupacional del encuestado/a al momento de la encuesta y la de su padre; la última en el caso de la encuesta de 1961 y la que tenía cuando el/la encuestado/a tenía 16 años en las otras. Estas encuestas permitieron aproximarnos al análisis de la influencia del origen nacional familiar y el lugar de nacimiento del encuestado/a en las pautas de movilidad social intergeneracional. La encuesta de 1961 incluía indicadores sobre el país de nacimiento de dos generaciones (encuestado y sus padres), y las encuestas del siglo XXI, tres generaciones (abuelos/padres/hijo/a encuestado/a).

En segundo lugar, se realizaron entrevistas biográficas con familias migrantes gallegas que llegaron a Buenos Aires en los años 50-60 y sus descendientes (migrantes, hijos/as o nietos/as), incluyendo alguna familia migrada hacia fines de la primera corriente migratoria (1930 y 1937) como transición y punto de contraste ${ }^{2}$. El trabajo de campo se realizó en la ciudad de Buenos Aires y el Conurbano Bonaerense en 2012, 2014 y 2018. En un primer momento, se contactó con informantes clave de asociaciones gallegas (Casa de Galicia, Asociación Mutualistas Residentes de Vigo, Federación de Sociedades Gallegas), lo cual permitió acceder a algunas personas entrevistadas, e igualmente se

2. El trabajo de campo se llevó a cabo en el marco de los proyectos Género, transnacionalismo y estrategias intergeneracionales de movilidad social (Oso, dir. 2011-2014) y Género, movilidades cruzadas y dinámicas transnacionales (Oso, dir. 2015-2019). Financiados por el Ministerio de Economía y Competitividad (referencias: FEM2011-26110 y FEM2015-67164-R). El trabajo fue realizado igualmente gracias al Programa de Consolidación e estructuración de unidades de investigación competitivas, Xunta de Galicia (GRC2014/048). 
recurrió a contactos personales para abrir el círculo a familias no relacionadas con el mundo asociativo. En total, 34 personas fueron contactadas a lo largo del trabajo de campo.

\section{Movilidad social de familias de origen español}

En esta sección analizamos tasas de movilidad social intergeneracional de la población de origen español en el Área Metropolitana de Buenos Aires, identificando a la población migrante de España y de ascendencia española en las generaciones precedentes. Medimos su peso relativo en el conjunto de la población y comparamos sus pautas de inserción en la estructura de estratificación de clases con relación a otros grupos según origen nacional.

Entrada la segunda mitad del siglo XX, el Ârea Metropolitana de Buenos Aires (Ciudad de Buenos Aires y Conurbano Bonaerense) exhibía una fuerte influencia sociocultural europea producto de las oleadas migratorias entre $1870-1930$ y $1945-1958$. La encuesta de 1961 nos brinda un panorama de dicho influjo. Tomando en consideración dos generaciones, tres cuartas partes de la población tenía ascendencia europea (76\%). El aporte demográfico y cultural de la migración gallega fue, sin dudas, muy significativo. Casi un cuarto de la población del AMBA era de origen español (24\%), del cual — según estimaciones de estudios precedentes citados- alrededor de dos tercios (70\%) eran de origen gallego. Casi la mitad había nacido en España y migrado a Buenos Aires; su peso relativo en el AMBA era de alrededor de $10 \%$, el 14\% restante se dividía entre los argentinos, hijos/as de padres españoles $(8 \%)$, y los argentinos con padres de origen nacional mixto $(6 \%)$, entre los cuales se destaca el tipo familiar padre español y madre argentina, dado el perfil masculino en edades activas de las primeras corrientes migratorias. Aunque con un porcentaje bastante menor, también se destacan las uniones entre españoles e italianos.

A continuación, nos detenemos en la inserción en la estructura de estratificación de clases de los migrantes españoles y sus hijos/as en relación con los nativos del AMBA, otros grupos migrantes y sus descendientes. A mediados del siglo XX, una de las tesis predominantes sobre la relación entre integración sociocultural y movilidad social en las sociedades de inmigración masiva como Estados Unidos y Argentina planteaba «la asimilación lineal». Según dicha tesis, en una estructura social abierta los grupos de distinto origen migratorio iban ocupando posiciones de clase de mayor jerarquía, en función del tiempo transcurrido desde la llegada a la sociedad de destino. En ese esquema analítico, los hijos/as de migrantes nacidos en el país tendrían mayores oportunidades de ascender socialmente y los migrantes recién llegados se insertarían en las posiciones más bajas de la estructura de clases, generando un «efecto de empuje hacia arriba» sobre los nativos (Germani, 1963). El ascenso social, en dicha perspectiva, era una cuestión de tiempo, aquel que el grupo migratorio tardara en internalizar las pautas culturales de la sociedad de destino. El cuadro 1 permite aproximarnos a dicha idea en el AMBA en 1961. 
Cuadro 1. Posición en la estructura de estratificación de clases según origen nacional familiar y lugar de nacimiento. Jefes/as de hogar residentes en el AMBA en 1961 (en \%)

\begin{tabular}{|c|c|c|c|c|c|c|c|c|}
\hline \multirow[b]{2}{*}{ Posición de clase } & \multicolumn{7}{|c|}{ Origen nacional familiar y lugar de nacimiento del/de la jefe/a de hogar* } & \multirow[b]{2}{*}{ Total } \\
\hline & $\begin{array}{c}\text { AMBA, } \\
\text { padres } \\
\text { argentinos }\end{array}$ & $\begin{array}{l}\text { AMBA, padres } \\
\text { migrantes } \\
\text { europeos } \\
\text { (uno } 0 \text { ambos) }\end{array}$ & $\begin{array}{c}\text { Migrantes } \\
\text { internos, padres } \\
\text { migrantes } \\
\text { europeos } \\
\text { (uno o ambos) }\end{array}$ & $\begin{array}{c}\text { Migrantes } \\
\text { europeos }\end{array}$ & $\begin{array}{c}\text { Hijos/as de } \\
\text { migrantes } \\
\text { españoles }\end{array}$ & $\begin{array}{l}\text { Migrantes } \\
\text { españoles }\end{array}$ & $\begin{array}{l}\text { Migrantes } \\
\text { internos, } \\
\text { padres } \\
\text { argentinos }\end{array}$ & \\
\hline $\begin{array}{l}\text { Empresarios/as, } \\
\text { profesionales y } \\
\text { directivos/as }\end{array}$ & 34,4 & 24,3 & 17,1 & 9,1 & 26,9 & 5,2 & 13,2 & 17,7 \\
\hline $\begin{array}{l}\text { Técnicos/as, } \\
\text { empleados/as } \\
\text { y dueños/as de } \\
\text { comercios/talleres } \\
\text { pequeños }\end{array}$ & 34,4 & 37,8 & 34,1 & 33,5 & 38,5 & 33,7 & 22,1 & 33,1 \\
\hline $\begin{array}{l}\text { Artesanos/as } \\
\text { de oficio } \\
\text { y obreros/as } \\
\text { calificados }\end{array}$ & 24,2 & 29,7 & 34,6 & 39,8 & 23,5 & 36,6 & 45,7 & 35,8 \\
\hline $\begin{array}{l}\text { Obreros/as no } \\
\text { calificados/as } \\
\text { y peones }\end{array}$ & 7,0 & 8,3 & 14,2 & 17,6 & 11,1 & 24,4 & 19,0 & 13,5 \\
\hline Total & 100,0 & 100,0 & 100,0 & 100,0 & 100,0 & 100,0 & 100,0 & 100 \\
\hline
\end{tabular}

* La composición por sexo de los jefes de hogar era 92\% varones y $8 \%$ mujeres.

Fuente: encuesta de Estratificación y Movilidad Social en el GBA, 1961.

El grupo mejor posicionado en la estructura de estratificación de clases es el de nativos del AMBA cuyos padres también era originarios de la región: se trata de familias de origen europeo y criollas ya asentadas en el país hace varias décadas. En lo que refiere a los inmigrantes europeos y sus hijos/as, parece corroborarse la hipótesis de la «asimilación lineal». Nos detendremos en examinar a los migrantes españoles y sus hijos/as. Dos tercios (66\%) de los hijos/as de los inmigrantes españoles que llegaron en las primeras oleadas a fines del siglo XIX y principios del siglo XX, en 1961 ya se encontraban en las clases medias. En cambio, los inmigrantes de arribo más reciente se ubicaban en las clases populares, principalmente el 39,8\% eran obreros calificados y trabajadores por cuenta propia con oficio, sin embargo, el 33,8\% ya pertenecían al estrato inferior de clases medias al que habían accedido principalmente a través de la instalación de pequeños comercios del ámbito gastronómico (bares, panaderías y restaurantes).

Una imagen de los rasgos distintivos de las trayectorias de clase de los migrantes españoles surge al compararlas con las trayectorias de migrantes italianos, ambos grupos constituían los de mayor importancia demográfica y cultural en la región. Para ello, recortamos el subgrupo de personas de origen de clase popular de ambos grupos (cuadro 2). 
Cuadro 2. Tasas de movilidad social intergeneracional de migrantes de origen de clase popular españoles/as e italianos/as. AMBA: 1961

\begin{tabular}{lccccc}
\hline & $\begin{array}{c}\text { Reproducción } \\
\text { en clase obrera } \\
\text { calificada }\end{array}$ & $\begin{array}{c}\text { Ascenso desde } \\
\text { orígenes rurales a la } \\
\text { clase obrera calificada }\end{array}$ & $\begin{array}{c}\text { Ascenso a la } \\
\text { clase media } \\
\text { vía pequeña } \\
\text { propiedad de } \\
\text { capital }\end{array}$ & $\begin{array}{c}\text { Ascenso a clase } \\
\text { media alta vía } \\
\text { credenciales } \\
\text { profesionales y } \\
\text { empresas medianas }\end{array}$ & $\begin{array}{c}\text { Ascenso a } \\
\text { clase alta vía } \\
\text { empresas } \\
\text { grandes }\end{array}$ \\
\hline Migrantes españoles/as & $49 \%$ & $35 \%$ & $32 \%$ & $6 \%$ & $0 \%$ \\
Migrantes italianos/as & $49 \%$ & $50 \%$ & $24 \%$ & $6 \%$ & $3 \%$ \\
\hline
\end{tabular}

Fuente: encuesta de Estratificación y Movilidad Social en el GBA, 1961.

Entre los italianos se destaca el ascenso social a través del empleo fabril y en la construcción (55\%); en cambio entre los españoles, en gran medida gallegos, sobresale la movilidad al estrato inferior de las clases medias a través del desarrollo de pequeñas empresas familiares que requieren poca inversión. Es de destacar que ambos grupos tuvieron una probabilidad similar de ascenso a las clases medias privilegiadas (6\%), pero entre los italianos fue posible el acceso a la clase alta en la primera generación vía la formación de grandes empresas de más de 50 empleados (3\%) y no entre los españoles.

El estudio de Moya (2004) brinda un diagnóstico detallado de las pautas de movilidad social de los españoles correspondientes al primer aluvión inmigratorio (1860-1930) y sus hijos/as que aún se reflejaba en las pautas de la encuesta de 1961.

En todas las muestras (...) los que ascendían siempre superaban a los que bajaban... En general el ascenso era un proceso gradual; los que estaban abajo ascendían a niveles intermedios, los que estaban en el medio subían a los escalones altos. Sin embargo, el $24 \%$ - $48 \%$ si se excluye la muestra de la Primera Guerra Mundial- de los obreros manuales ascendieron a categorías no manuales, otro ascenso notable en comparación con las pautas del mundo en esa época. Entre las mujeres nacidas en España, el 43\% en 1920 y el 42\% en 1930 trabajaban como sirvientas, pero únicamente el 13\% y el 9\% de las hijas hacían lo mismo (Moya, 2004: 277).

Respecto de la movilidad intrageneracional de los migrantes, Moya destaca que la pauta de inmovilidad ocupacional a menudo escondía avances importantes entre escalones.

En el Hotel Plaza

[...] hubo dos rutas de ascenso ocupacional: el camino gallego, en las tareas de servicio en el hotel, y el camino italiano, en las tareas de mantenimiento. Más aún, dentro del camino gallego, estas personas podían enumerar ocho pasos diferentes, desde botones hasta jefes de mozos, y entre las mujeres el pasaje de sirvienta a valet de recámara o ama de llaves también implicaba avances sustantivos (Moya, 2004: 277). 
Si tomamos una perspectiva holística considerando los cambios ocupacionales intra e intergeneracionales, la migración a Buenos Aires para muchas familias implicó un ascenso social de larga distancia:

Fueron pocos lo que se convirtieron en Anchorena o bailaron el tango en el Plaza. Pero muchos ahorraron algunos pesos, giraron millones a su tierra natal, criaron familias y se convirtieron en padres y madres de maestras y contadores. Para la gran mayoría de los habitantes de aquella época eso significaba un ascenso social; para los inmigrantes eso era: hacer la América (Moya, 1952: 289).

Estas pautas reflejan la movilidad social de los españoles y sus descendientes durante la época de la formación de la sociedad argentina moderna y su expansión a través de la industrialización por sustitución de importaciones. ¿Qué permanece de ello en la Buenos Aires actual? ¿Cómo fueron las trayectorias de movilidad social de las familias españolas pertenecientes a la corriente migratoria más reciente? ¿¿Se mantienen las pautas del periodo de la migración masiva? El análisis de las encuestas de 2005, 2010 y 2015 nos acerca a estos interrogantes, para ubicar a los descendientes de familias españolas en la estructura de estratificación de clase de comienzos del XXI.

Medio siglo más tarde el peso relativo de la población con ascendencia europea descendió ${ }^{3}$, producto de la finalización de los flujos migratorios desde varias décadas (1960), el fallecimiento de las generaciones migrantes y el crecimiento de la población nativa y de corrientes migratorias de países latinoamericanos que, desde mediados de los 70 , cambiaron su patrón de asentamiento desde zonas fronterizas hacia los grandes centros urbanos. De todos modos, entre la población del AMBA en 2010 (promedio), casi la mitad aún conserva ascendencia directa en una o dos generaciones atrás de la migración europea (alcanzando casi el 50\%). En este marco, la población del AMBA con origen o aporte migratorio español en sus familias aún tiene un peso sustantivo, casi dos de cada diez habitantes, el 17,4\% (cuadro 4).

El grupo mayoritario, en la actualidad, corresponde a los nietos/as de inmigrantes españoles, (13\%), mayoritariamente de origen gallego. Si nos detenemos en los orígenes de los nietos/as, encontramos que se dividen en partes iguales entre aquellos que provienen de familias con ascendencia española, por parte de sus cuatro abuelos/as o mixtas con argentinos (6,6\%), y de familias europeas mixtas $(6,3 \%)$, donde prevalecen las uniones matrimoniales entre españoles e italianos. La proporción de los hijos/as de inmigrantes españoles

3. Las encuestas no permiten identificar un sector de la subpoblación de tercera generación de argentinos que tienen origen europeo en la cuarta generación hacia atrás — sobre todo entre las cohortes más jóvenes- debido a que, como señalamos, el primer ciclo de la migración europea masiva tuvo lugar entre 1870 y 1930. En dicha subpoblación una proporción seguramente tiene ascendencia gallega aunque a los fines de este trabajo no es relevante porque se trata de un grupo con varias generaciones de socialización en el país. 
Cuadro 4. Posición en la estructura de estratificación de clases según origen nacional familiar. Personas de ambos sexos mayores de 25 años residentes en el AMBA: 2005, 2010, 2015 (en \%)

\begin{tabular}{|c|c|c|c|c|c|c|c|c|c|c|c|}
\hline $\begin{array}{l}\text { Posición } \\
\text { de clase }\end{array}$ & $\begin{array}{c}\text { Tres } \\
\text { generaciones } \\
\text { de argentinos }\end{array}$ & $\begin{array}{c}\text { Hijos/as } \\
\text { de europeos } \\
\text { (no españoles) }\end{array}$ & $\begin{array}{c}\text { Nietos/as } \\
\text { de europeos } \\
\text { (no españoles) }\end{array}$ & $\begin{array}{l}\text { Hijos/as de } \\
\text { españoles d }\end{array}$ & $\begin{array}{l}\text { Nietos/as } \\
\text { le españoles }\end{array}$ & $\begin{array}{c}\text { Nietos/as de } \\
\text { españoles y } \\
\text { otros grupos } \\
\text { europeos }\end{array}$ & $\begin{array}{l}\text { Migrantes } \\
\text { latinoam. }\end{array}$ & $\begin{array}{l}\text { Hijos/as de } \\
\text { latinoam. }\end{array}$ & $\begin{array}{l}\text { Nietos/as } \\
\text { latinoam. }\end{array}$ & $\begin{array}{r}\text { Migrantes } \\
\text { europeos }\end{array}$ & Total \\
\hline $\begin{array}{l}\text { Directivos/as, } \\
\text { profesionales, } \\
\text { empresarios/as }\end{array}$ & 18,9 & 28,0 & 30,7 & 23,0 & 34,8 & 33,8 & 10,7 & 17,1 & 16,7 & 14,3 & 23,0 \\
\hline $\begin{array}{l}\text { Pequeños } \\
\text { comerciantes, } \\
\text { técnicos, } \\
\text { empleados/as }\end{array}$ & 28,3 & 29,5 & 39,6 & 41,9 & 33,3 & 33,1 & 19,8 & 23,1 & 25,0 & 42,9 & 30,7 \\
\hline $\begin{array}{l}\text { Obreros/as } \\
\text { calificados }\end{array}$ & 21,9 & 28,5 & 16,0 & 25,7 & 16,3 & 18,4 & 33,9 & 25,6 & 25,0 & 21,4 & 22,1 \\
\hline $\begin{array}{l}\text { Obreros/as no } \\
\text { calificados }\end{array}$ & 31,0 & 14,0 & 13,8 & 9,5 & 15,6 & 14,7 & 35,5 & 34,2 & 33,3 & 21,4 & 24,3 \\
\hline Total & 100 & 100 & 100 & 100 & 100 & 100 & 100 & 100 & 100 & 100 & 100 \\
\hline \multirow[t]{2}{*}{$\mathrm{N}$} & 923 & 193 & 326 & 74 & 141 & 136 & 121 & 117 & 48 & 42 & 2121 \\
\hline & 43,5 & 9,1 & 15,4 & 3,5 & 6,6 & 6,4 & 5,7 & 5,5 & 2,3 & 2,0 & 100 \\
\hline
\end{tabular}

Fuente: encuestas del IIGG-UBA, 2005, 2010 y 2015.

es sustancialmente menor, el 3,5\%, y se trata sobre todo de los hijos/as de la última corriente migratoria española (principalmente gallega) que tuvo lugar entre 1940 y 1962. El porcentaje de migrantes españoles apenas ronda el 1\% debido al cierre del ciclo migratorio; se trata de una población envejecida. Analicemos a continuación la inserción de clase de los hijos/as y nietos/as de migrantes españoles (cuadro 4).

Los hijos/as de inmigrantes españoles tienen mayor presencia relativa en el estrato inferior de clase media, conformado por pequeños comerciantes, técnicos y empleados (41,9\%). Muchos hijos/as de migrantes españoles de origen de clase popular ascendieron socialmente a través de la realización de carreras terciarias e insertándose como docentes y empleados/as de cuello blanco, pauta compartida con otros grupos de origen europeo; pero a través de un examen detallado observamos que, en una proporción mayor, los hijos/as de españoles continuaron el emprendimiento comercial de sus progenitores en el terreno gastronómico y de hotelería. Segundo, alrededor de un cuarto $(23 \%)$ de los hijos de españoles alcanzaron la clase media privilegiada a través de puestos directivos y profesionales $(25,9 \%)$ mediante la obtención de títulos universitarios. Esta pauta es compartida con los hijos/ as de migrantes europeos de otras nacionalidades, aunque en estos últimos es más acentuada. Tercero, si bien el porcentaje de inserción en la clase obrera calificada es importante $(25,7 \%)$, es algo menor que en los hijos/as de migrantes europeos de otras nacionalidades. Por último, cabe destacar que la proporción de los hijos/as de migrantes españoles en el estrato de obreros/ as no calificados es sustancialmente menor al de otros grupos (9,5\%), lo 
cual sugiere la transmisión intergeneracional de recursos materiales, sociales o culturales que protegieron del descenso de clase (profundizaremos en la sección de análisis cualitativo).

Al comparar los datos de 2005/15 con los de 1961, observamos que los hijos/as de migrantes españoles de la última corriente migratoria se insertan levemente en menor proporción en la clase media profesional y directiva $(23 \%$ vs. $26,9 \%)$ y un poco más en la clase intermedia de técnicos/empleados/as y pequeños comerciantes ( $41,9 \%$ vs. $38,5 \%)$. Estas pautas sugieren que las familias pertenecientes a la corriente migratoria más reciente arribaron a una estructura social más consolidada, y probablemente más cerrada, por lo cual recorrieron en promedio trayectorias de movilidad social ascendente de más corta distancia.

En los dos grupos de nietos/as de migrantes españoles (con origen español en sus cuatro abuelos/as o mixtas con argentinos, y de familias europeas mixtas), destaca la pauta de un mayor acceso relativo a la clase directiva, profesional y empresarial (34,8\% y 33,8\% respectivamente). Este incremento en la participación en la clase media de mayor estatus en la generación de los nietos/as de españoles da cuenta de la continuación de procesos de movilidad social ascendente.

En suma, si tomamos en consideración que entre el $80 \%$ y el $90 \%$ de los migrantes europeos eran de origen de clase popular (labradores/as, campesinos/as u obreros), es posible reseñar las siguientes pautas: 1) los migrantes españoles, al igual que otros grupos de origen europeo, tuvieron altas tasas de movilidad ascendente intrageneracional; 2) el camino gallego de movilidad ascendente en la primera generación fue en gran medida la instalación de comercios en el terreno gastronómico; 3) los hijos/as de españoles, al igual que otros grupos de origen europeo, tuvieron tasas altas de acceso a la clase profesional, directiva y empresarial; 4) entre los hijos/as de españoles pertenecientes a la última corriente migratoria la inserción en esta clase disminuyó levemente en el marco de una sociedad menos dinámica; 5) entre los hijos/as de padres de españoles (gallegos) de la última corriente migratoria es algo más alta la permanencia en la pequeña burguesía comercial; 6) los hijos/as de españoles permanecen o descienden menos a la clase obrera no calificada; 7) los nietos/as incrementan su participación en la clase profesional, directiva y empresaria. Como corolario se desprende que las familias de origen español (al igual que otras nacionalidades europeas) recorrieron trayectorias de movilidad social ascendente, que con el paso del tiempo fueron adquiriendo un carácter más «escalonado».

Si bien estas pautas muestran dónde se insertan los hijos/as y nietos/as de españoles en la estructura de estratificación social, no nos permiten ahondar en los caminos recorridos para acceder a posiciones de clases medias. ¿Qué estrategias familiares desplegaron? ¿Qué oportunidades y obstáculos se encontraron con relación a los ciclos económicos del país? A través del análisis de biografías familiares buscamos indagar estas dimensiones. 


\section{Proyectos, estrategias y trayectorias de movilidad de las familias migrantes gallegas}

La reconstrucción de biografías familiares permite comparar las diferentes estrategias de movilidad social intergeneracional ${ }^{4}$ que se pusieron en marcha por las familias de origen gallego y su impacto en las trayectorias de clase. Posibilita identificar cómo esas estrategias se van configurando a un lado y otro del Atlántico, en una articulación entre las movilidades geográficas y sociales. Para ello, del conjunto de personas entrevistadas, hemos seleccionado cuatro historias de familias con distintas trayectorias de clase (figura 1).

El principal argumento del análisis cualitativo se centra en que en un contexto se despliegan una serie de proyectos migratorios y estrategias de movilidad social que, junto a la estructura de oportunidades, van configurando las trayectorias de clase, articulándose diferentes factores en la configuración de los itinerarios de movilidad social de las familias gallegas en Buenos Aires. En primer lugar, presentaremos los proyectos migratorios y de movilidad social de

Figura 1. Trayectoria de clase de las familias seleccionadas

\begin{tabular}{|c|c|c|c|c|}
\hline & Familia Coco & Familia Esteban & Familia Ana & Familia Carmen \\
\hline $\begin{array}{l}\text { Migrantes } \\
\text { Estrategia } \\
\text { pequeña } \\
\text { empresa y } \\
\text { matrimonio } \\
\text { endogámico } \\
\text { Estrategia } \\
\text { de ahorro } \\
\text { e inversión }\end{array}$ & $\begin{array}{l}\text { Año de llegada: } 1930 \text { y } 1937 . \\
\text { José, padre de Coco: migra en } \\
1930 . \\
\text { Galicia: labraba el campo } \\
\text { y criaba algún animal. } \\
\text { Buenos Aires: } \\
\text { - Peón de almacén } \\
\text { - Lechero } \\
\text { - Bares (con socios gallegos) } \\
\text { - Hotel (socios gallegos) } \\
\text { Dolores (Lola), madre de Coco: } \\
\text { migra en 1937. } \\
\text { - Servicio doméstico } \\
\text { - Lavaba ropa para afuera } \\
\text { - Ayudaba en los comercios } \\
\text { Ahorros: inversión en propiedades } \\
\text { para alquilar en el país. }\end{array}$ & $\begin{array}{l}\text { Año migración: } 1950 \\
\text { Abuelo materno de Esteban. } \\
\text { Galicia: obrero en carpintería. } \\
\text { Buenos Aires: Pone su carpintería } \\
\text { (junto a un socio gallego). } \\
\text { Abuela materna: ama de casa. } \\
\text { Ahorros: compra su propia casa. } \\
\text { Padre de Esteban. } \\
\text { Año de migración: } 1970 . \\
\text { - Cuida al tío } \\
\text { - Empleado garaje del tío } \\
\text { - Hereda parte del garaje } \\
\text { - Hace negocios con la herencia } \\
\text { Ahorros: hace negocios y continúa } \\
\text { con el garaje. } \\
\text { Madre de Esteban: nace en Argentina } \\
\text { de padres gallegos, lleva a cabo } \\
\text { estudios que deja cuando se casa. }\end{array}$ & $\begin{array}{l}\text { Año de migración: } 1949 . \\
\text { Padre de Ana. } \\
\text { Galicia: trabajaba en el } \\
\text { campo. } \\
\text { Buenos Aires: empieza } \\
\text { de camarero asalariado y } \\
\text { luego pone un bar. } \\
\text { - Madre de Ana: } \\
\text { - Servicio doméstico } \\
\text { - Ama de casa } \\
\text { - Ayuda en el bar } \\
\text { Ahorros: Invierten en } \\
\text { propiedades para alquilar } \\
\text { en Buenos Aires. }\end{array}$ & $\begin{array}{l}\text { Año de migración: } 1950 . \\
\text { El abuelo migra primero y } \\
\text { después llama a la mujer } \\
\text { y los hijos. } \\
\text { Abuelo: es carpintero } \\
\text { en Galicia y sigue siendo } \\
\text { carpintero asalariado en } \\
\text { Buenos Aires. } \\
\text { Abuela: ama de casa. } \\
\text { Ahorros: no tienen ahorros. }\end{array}$ \\
\hline
\end{tabular}

4. A lo largo del análisis hemos tenido en cuenta tres generaciones: 1) migrantes: la mayoría de ellos corresponden a la última corriente migratoria que arribó a Argentina entre 1940 y 1960; hemos elegido una familia que migró en los años 30 debido a que aporta un punto de comparación para poder entender la dinámica de las migraciones posteriores; 2) hijos/as de migrantes: son los descendientes de los migrantes, pueden ser de dos tipos: a) migrantes, que nacieron en Galicia y se desplazaron a Argentina, reagrupados por su/s padre/madre/s; b) descendientes que nacieron ya en Buenos Aires, tras la emigración de su/s padre/madre/s; 3) nietos/as de los migrantes, nacidos en Argentina. Cabe señalar que podemos encontrar casos en los cuales los descendientes sean hijos/as y nietos/as de migrantes, a la vez. 
Figura 1. Trayectoria de clase de las familias seleccionadas (continuación)

\begin{tabular}{|c|c|c|c|c|}
\hline & Familia Coco & Familia Esteban & Familia Ana & Familia Carmen \\
\hline $\begin{array}{l}\text { Hijos/as de } \\
\text { migrantes } \\
\text { Aparece la } \\
\text { estrategia } \\
\text { educativa } \\
\text { y continúa } \\
\text { la pequeña } \\
\text { empresa }\end{array}$ & $\begin{array}{l}\text { Hijos/as, Coco y Aida } \\
\text { Coco: abogado y comerciante. } \\
\text { - Abogado (Universidad } \\
\text { de Buenos Aires) } \\
\text { - Comercio de telas con } \\
\text { el cuñado } \\
\text { Se casa tiene un hijo. } \\
\text { Aida: } \\
\text { - Se casa tiene dos hijos } \\
\text { - Estudió (no se recibió) } \\
\text { - Jefa de sección en Aerolíneas } \\
\text { Argentinas }\end{array}$ & $\begin{array}{l}\text { Hijos y nietos (a la vez): Esteban y } \\
\text { su hermano. } \\
\text { Esteban: administración de empresa. } \\
\text { Hermano: músico. } \\
\text { Administran un bar vinculado a la } \\
\text { comunidad gallega en Buenos Aires. }\end{array}$ & $\begin{array}{l}\text { Hijos/as: Ana y su } \\
\text { hermano. } \\
\text { Ana: estudió secundaria } \\
\text { y para contadora en la } \\
\text { universidad, pero no deja } \\
\text { los estudios cuando se } \\
\text { casa. Trabaja con el marido } \\
\text { en seguros hasta que } \\
\text { llega la crisis de } 2001 \text { y el } \\
\text { marido se queda en paro. } \\
\text { Montan un bar en un local } \\
\text { que les ceden los padres } \\
\text { de Ana. } \\
\text { Hermano de Ana: Estudió } \\
\text { secundaria, taxista. }\end{array}$ & $\begin{array}{l}\text { Hijos/as: cinco (tres } \\
\text { mujeres y dos hombres) } \\
\text { nacen en Galicia y migran } \\
\text { reagrupados por los padres. } \\
\text { Dos hijas más nacen en } \\
\text { Buenos Aires. } \\
\text { Fernanda (hermana } \\
\text { mayor). } \\
\text {-Tenía un almacén } \\
\text { - Muere } \\
\text { Madre de Carmen } \\
\text { (Ilega con 13 años } \\
\text { segundogénita): } \\
\text { - Servicio doméstico } \\
\text { - Asalariada en un taller } \\
\text { - Se casa (transportista) y } \\
\text { tiene tres hijas (hermana } \\
\text { mayor, Carmen y hermana } \\
\text { menor) } \\
\text { - Hereda de Fernanda } \\
\text { - Cuida a la hija } \\
\text { discapacitada de Fernanda } \\
\text { y administra sus bienes } \\
\text { Hermanas menores (3): } \\
\text { una llega pequeña. Dos de } \\
\text { ellas nacen en Argentina. } \\
\text { Estudian hasta secundaria } \\
\text { y se casan con maridos } \\
\text { argentinos. } \\
\text { Hermanos (2): realizan } \\
\text { trabajos manuales como } \\
\text { asalariados. }\end{array}$ \\
\hline $\begin{array}{l}\text { Nietos/as de } \\
\text { migrantes } \\
\text { Revalorización } \\
\text { de la estrategia } \\
\text { educativa } \\
\text { vs. no revalori- } \\
\text { zación y «retor- } \\
\text { no a las raíces» } \\
\text { (migración a } \\
\text { España) }\end{array}$ & $\begin{array}{l}\text { Nietos: } \\
\text { Hijo de Coco: ingeniero. } \\
\text { Hijo de Aída: investigador } \\
\text { y profesor universitario. } \\
\text { Hijo de Aída: diseñador } \\
\text { y arquitecto. }\end{array}$ & $\begin{array}{l}\text { Nietos: } \\
\text { Esteban y su hermano, además de } \\
\text { hijos de padre migrante, son nietos } \\
\text { de la migración gallega (por parte de } \\
\text { los abuelos maternos). }\end{array}$ & $\begin{array}{l}\text { Nietos/as: estudiaron en } \\
\text { la universidad, pero con la } \\
\text { crisis de } 2001 \text { migran a } \\
\text { España. } \\
\text { Hijo de Ana: empleado } \\
\text { de seguridad en Galicia. } \\
\text { Hija de Ana: cajera de } \\
\text { supermercado en Galicia. }\end{array}$ & $\begin{array}{l}\text { Nietos/as: } \\
\text { Carmen: estudios } \\
\text { universitarios. } \\
\text { Hermana de Carmen: } \\
\text { estudios terciarios de } \\
\text { magisterio. } \\
\text { Sus primos: Solo una } \\
\text { estudia en la universidad. } \\
\text { Tres de ellos migran a } \\
\text { España tras la crisis de } \\
\text { 2001. Realizan trabajos } \\
\text { manuales. }\end{array}$ \\
\hline
\end{tabular}

Fuente: elaboración propia sobre la base de los datos del trabajo de campo. 
la migración gallega a Argentina. En segundo lugar, analizaremos cinco estrategias de movilidad social: la estrategia empresarial y patrimonial; la estrategia matrimonial; la estrategia educativa; el papel del capital social como soporte de los procesos de movilidad y la estrategia de movilidad espacial o «retorno a las raíces». Por último, trazamos las trayectorias intergeneracionales de movilidad social de las cuatro familias seleccionadas.

\section{1. "Hacer las Américas»: un proyecto migratorio a largo plazo}

Los movimientos migratorios a ultramar tienen sus orígenes en la estructura económica y social de Galicia del siglo XIX, fundamentada, según Bertrand (1999), en una sociedad campesina con un sistema de transmisión de las explotaciones agrarias no igualitario (basada en el sistema de foros). La generalización de un celibato campesino, para aquellos hijos sin posibilidades de herencia, hacía que estos estuviesen disponibles para migrar en búsqueda de rentas y de mayores facilidades para desarrollar una vida matrimonial. En el siglo XX este sistema deriva en otro basado en la subdivisión de la tierra, que genera la multiplicación de minifundios, cuya explotación no alcanza a cubrir las necesidades de reproducción familiar, por lo que muchos (sobre todo varones) migran. Además, la herencia de una cultura de la emigración permanecería anclada en la sociedad gallega (Bertrand, 1999). No obstante, este sistema migratorio no se reproduce de la misma manera. En efecto, la emigración continental en la década de 1960 se inserta, según Bertrand (1999), en «un nuevo modelo migratorio definido por su carácter circunstancial, transitorio, temporal» (p. 448), que trae consigo retornos continuos a las parroquias de origen ${ }^{5}$. La comparación con la migración europea es útil para sacar a la luz que mientras los migrantes que tomaron rumbo a Europa lo hicieron con carácter marcadamente temporal, con una fuerte presencia del «mito del retorno» (Oso, 2004), los migrantes de ultramar presentaban un proyecto migratorio que requería de un asentamiento más a largo plazo en el país de destino: el proyecto de movilidad social estaba fundamentado en invertir en América. La migración a Argentina entre 1880-1930 se encontró con una sociedad dinámica que multiplicaba oportunidades educativas y ocupacionales, lo que favorecía la puesta en marcha de emprendimientos comerciales. Veamos cómo se articuló, en el caso de la emigración gallega a Argentina, este proyecto migratorio con las estrategias de movilidad social desarrolladas por los migrantes.

\subsection{Estrategias intergeneracionales de movilidad social}

\subsubsection{La estrategia empresarial y patrimonial}

Una de las principales estrategias de movilidad social de los gallegos en Argentina fue la empresarial, que la diferencia, en buena medida, de la migración

5. Esta temporalidad de la migración continental estuvo condicionada por la canalización de estas corrientes migratorias a través de la política de «trabajadores invitados» que se desarrolló en los países europeos y fue sostenida igualmente por el gobierno franquista (Oso, 2004). 
a Europa, apoyada en el trabajo asalariado, donde los emprendimientos eran minoritarios. Instalar pequeños comercios, principalmente gastronómicos o talleres, fue una de las vías de ascenso de los migrantes europeos de origen de clase popular en Argentina. Según Nuñez Seixas (2007), el éxito de los comercios de gallegos se basó en las bajas necesidades de inversión inicial y la expansión del comercio minorista o intermediario, la garantía que otorgaba disponer de cierto mercado conformado por los propios migrantes para productos gallegos o españoles y la densidad de las redes microsociales de paisanaje y vecindad, que brindaban entreayudas y limitaban la competencia. La maximización de márgenes de beneficio se fundamentó en la autoexplotación personal y la incorporación de mano de obra migrante (que se caracterizaba por ser más barata y de mayor confianza, basada en el compromiso con el negocio al compartir propietarios y empleados una expectativa de rápido ascenso social dentro del ramo de actividad). En palabras de este autor: «Esa ascensión social no siempre llevaba a convertirse en propietario de una gran empresa. Pero sí podía suponer pasar de mozo a propietario o copropietario de una panadería, de una confitería, de un horno o una pequeña empresa panificadora» (Nuñez Seixas, 2007: 38-39). La estrategia empresarial gallega se caracterizó igualmente por el establecimiento de un sistema de sociedades que estaba fundamentado en la unión de capitales para la puesta en marcha de negocios por parte de socios pertenecientes a la comunidad gallega. Eran sociedades que funcionaban de palabra y estaban basadas en la confianza de las redes comunitarias. Esta estrategia empresarial se sustentó igualmente en el desarrollo de una vida austera, que potenciaba el ahorro y la inversión del dinero fundamentalmente en bienes patrimoniales (Dalle, 2016). Veamos cómo se plasmó la estrategia empresarial en el caso de las familias entrevistadas.

Los padres de Coco parten de Galicia en la década de 1930. Se reencuentran y se casan en Buenos Aires. El padre de Coco comenzó trabajando de peón de almacén y luego de ayudante de lechero, hasta que aprendió el oficio y se puso por su cuenta. La madre trabajaba inicialmente como empleada doméstica. Durante las décadas de 1950 y 1960, bajo el impulso industrialista del primer peronismo y el desarrollismo, Buenos Aires continuó su proceso de expansión. Con él florecían actividades comerciales y la familia fue progresando económicamente y, junto a socios paisanos, compró bares donde trabajaban los diferentes miembros de la familia. Cuando los hijos/as eran pequeños, la madre lavaba ropa para otras familias del barrio. Luego ayudó al padre en sus comercios, como las esposas de sus socios paisanos. Trabajaban un comercio por vez, «día y noche», lo «levantaban» y luego lo vendían. Años más tarde, junto a su compadre de toda la vida, el padre de Coco tuvo un hotel. La familia invirtió sus ahorros, labrados con trabajo duro y una vida austera en propiedades. «Los gallegos no sabían de sistema financiero, invertían en ladrillos».

Los padres de Ana migran desde Galicia a finales de la década de 1940. Se conocen y se casan en Buenos Aires y tiene dos hijos/as (Ana y su hermano). El padre, después de pasar por el empleo en la restauración como asalariado, decide montar su propio bar. La madre, que al llegar a Argentina trabajó en 
servicio doméstico, una vez tiene a sus hijos/as y mientras los niños son pequeños, es ama de casa y se dedicaba a las labores de cuidado y del hogar. Con la ampliación de la avenida 9 de Julio, la pareja pierde el local del negocio y montan un nuevo bar en la misma casa que habían construido y donde vivían. A partir de ese momento, la madre de Ana empieza a trabajar en el negocio familiar. Todas las inversiones realizadas por la pareja fueron para la compra de bienes inmuebles, con el destino de alquilarlos y obtener rentas.

El padre de Esteban llega a Argentina en 1970. Un tío migrante, que gozaba de buena posición, enferma y le «reclama» ${ }^{6}$ para cuidarle. Al llegar a Buenos Aires empieza a trabajar en el garaje propiedad del tío, y se ocupa de él hasta que fallece. En agradecimiento, hereda de este familiar una parte del garaje, lo cual supone un impulso que genera un encadenamiento de emprendimientos (compra departamentos que alquila) que le garantiza una buena posición social. En la colectividad, conoce a una hija de gallegos, con la que se casa y tienen dos hijos/as (Esteban y su hermano). Como vemos, Esteban y su hermano ocupan una doble posición: son hijos y nietos de gallegos. En la historia del abuelo materno también se observa la estrategia emprendedora característica de la colectividad. El abuelo de Esteban migra a Buenos Aires en 1950, donde conoce a su mujer gallega, que trabajaba en servicio doméstico, y tienen una hija, la madre de Esteban. En Galicia era carpintero y, al llegar a Buenos Aires, empieza a trabajar como asalariado en una carpintería. Con un socio, abren un taller que comparten y posteriormente compran una casa donde viven las dos familias. A diferencia del padre de Esteban, el abuelo materno, solo consigue una movilidad social de corta distancia, porque no dispone de capital patrimonial (que sí hereda el padre de Esteban de su tío). Pero ambos utilizan la estrategia empresarial como la principal vía de ascenso social.

Las historias familiares muestran cómo, aunque los hombres establecían las sociedades empresariales y protagonizaban los emprendimientos, las mujeres trabajaban en los negocios familiares (bares, hoteles, etcétera), apoyando la estrategia empresarial. Por lo general, iniciaban su trayectoria laboral como asalariadas en el servicio doméstico, empleo que solían dejar con la maternidad. Algunas combinaban las labores domésticas y el cuidado de hijos/as con trabajos que podían hacer desde casa (lavar ropa, costura, etcétera), y trabajando en el negocio familiar una vez crecían los descendientes (caso de las madres de Coco, Ana y de la abuela de Esteban).

Como vemos, las cadenas empresariales de gallegos fueron una de las principales vías distintivas de movilidad social en Argentina. Lo relevante es cómo estas cadenas se han ido construyendo a lo largo de las diferentes corrientes migratorias. Se implantaron ya en las primeras migraciones a Argentina de principios del siglo XX, como muestra la historia familiar de Coco, y las redes migratorias fueron consolidando esta cultura y estrategia empresarial. La acumulación monetaria y patrimonial dio lugar a herencias, que amortiguaron los momentos de recesión económica, como muestra la familia de Carmen.

6. El reclamo era el pedido de autorización de migración. 
El abuelo de Carmen llega a Buenos Aires en los años cincuenta y se ocupa como carpintero asalariado, trabajo que ya realizaba en Galicia. Al poco tiempo llama a la mujer y a cinco hijos/as: Fernanda (hermana mayor), Paquita, (madre de Carmen, segundogénita), dos varones y una niña pequeña. En Argentina nacen dos hijas más. Del conjunto de los hermanos, Fernanda, la hermana mayor, es la que tuvo un mayor ascenso social, gracias a la estrategia gallega clásica de emprendimiento (montó un almacén). Cuando fallece, la hija discapacitada de Fernanda queda a cargo de Paquita, que asume la tutela oficialmente y pasa a administrar los bienes de la herencia, de forma que mejora la situación económica de la familia. Un nuevo caso de herencia en agradecimiento por los cuidados, como vimos en el caso del padre de Esteban. Pasemos a desarrollar la segunda de las principales estrategias de movilidad social puestas en marcha por la migración gallega en Argentina: la matrimonial.

\subsubsection{La estrategia matrimonial}

Entre los migrantes gallegos se observa una fuerte endogamia. Muchos de los pioneros del éxodo acaban casándose con otros compatriotas gallegos, uniones favorecidas por la densidad de las redes sociales de la colectividad en Buenos Aires (Farías, 2012). Estas uniones fueron igualmente homógamas en términos de clase social, de tal manera que «el matrimonio no constituyó una vía directa de movilidad ascendente a través del enlace con alguien que está en una posición de clase más alta, tanto en términos económicos como de mayor prestigio, más bien son parejas homógamas que tienen una aspiración de ascenso social y van armando un proyecto juntos» (Dalle, 2013: 382). Es el caso de los abuelos de Esteban y de los padres de Coco y Ana. Todos ellos migran solos, conocen a sus parejas gallegas en Buenos Aires y se casan. En los tres casos, los hombres eran trabajadores manuales asalariados cuando llegaron a Argentina, donde conocen a sus mujeres, ocupadas en el servicio doméstico. Queremos resaltar que la estrategia empresarial de movilidad social estuvo claramente apoyada en la conformación de estos matrimonios homógamos y endógamos. Según el modelo familiar de la época, el hombre se ocupaba inicialmente de las tareas productivas y la mujer de las reproductivas, pero apoyando igualmente en el negocio familiar. No obstante, esta endogamia matrimonial se va perdiendo en las siguientes generaciones, aunque no siempre. La historia de la familia de Carmen es un caso interesante. Muestra cómo influye la edad de llegada de los hijos/as a Argentina en la reproducción o no los matrimonios endogámicos, y saca a la luz que los hijos/as de migrantes que llegan pequeños o que nacen ya en Argentina participan en ámbitos de sociabilidad más abiertos, sobre todo a través de las instituciones educativas, que les permiten ir saliendo del «mercado matrimonial gallego».

Vimos como la madre de Carmen, Paquita, fue de las hermanas en su familia que llega a Argentina a una edad más avanzada (13 años). Se casa con un argentino transportista de hacienda, reproduciendo un matrimonio homógamo en términos de origen social. El esposo no tiene un trabajo lo suficientemente solvente, por lo que Paquita siempre tuvo un trabajo remunerado (cuidando 
niños y en una fábrica de pantalones), que compatibiliza con el cuidado de sus tres hijas. No obstante, la situación de sus hermanas menores es diferente. Una de ellas migró siendo muy pequeña, las otras dos nacieron ya en Argentina. Por ello, tuvieron la posibilidad de cursar hasta la educación secundaria, lo cual les abrió el paso en el mercado matrimonial. Así, vivieron un ascenso social vía matrimonio, ya que se casaron con maridos argentinos de posición económica solvente. No obstante, la vía de ascenso social matrimonial es inestable, dependiente y puede alterarse con el paro, el divorcio o la defunción del marido. En efecto, para las tres hermanas menores, la trayectoria de movilidad social se ve truncada cuando fallecen sus maridos o estos se quedan en paro. Actualmente, tienen que incorporarse al mercado de trabajo a edad avanzada, sin experiencia laboral previa, en un contexto donde los estudios secundarios no están tan valorados, y ocuparse en empleos no cualificados (cuidando niños, en la portería de colegios). Según Carmen, al final las hermanas pequeñas (sus tías) se insertan en el mismo tipo de trabajo que desarrollaron las mayores (su madre y su tía Fernanda) en su juventud. Veamos cómo, más allá de abrir las puertas del mercado matrimonial endogámico, la educación constituyó la principal vía de ascenso social para hijos/as y nietos/as de gallegos.

\subsubsection{La estrategia educativa de los descendientes de los migrantes}

Una vía central de ascenso de los hijos/as y nietos/as de inmigrantes europeos de origen de clase popular en Argentina fue la educación universitaria, que no es distintiva de la comunidad gallega, sino que es igualmente propia de otras colectividades de ultramar (Dalle, 2016). El título universitario sirvió para acceder a ocupaciones profesionales, y ascender en la carrera gerencial y administrativa. Veamos, no obstante, cómo la estrategia educativa, en el marco de los procesos migratorios, conlleva una complejidad que hace que para algunos descendientes haya sido una herramienta de ascenso social más útil que para otros.

\section{El logro educativo de los descendientes de gallegos}

La familia de Coco ilustra la vía de movilidad social ascendente de los hijos/ as y nietos/as de inmigrantes gallegos a través de la educación universitaria. Coco terminó los estudios de abogacía, y a su hermana le faltaron solo cuatro materias para recibirse de licenciada en Química, pero pudo hacer carrera en Aerolíneas Argentinas. Cuando Coco se licenció su padre lloró cuatro días seguidos. No podía entender cómo su hijo había llegado tan lejos. La obtención del título universitario significó un orgullo para la familia. ¿Qué factores posibilitaron este salto entre generaciones?

En primer lugar, el progreso económico de la familia a través de la instalación de bares con socios paisanos fue brindando una base de bienestar económico para que los hermanos pudiesen estudiar, lo cual pone de relieve que las estrategias que pusieron en marcha las familias gallegas en Buenos Aires no se desarrollan de forma aislada, sino que se articulan unas con otras, complementándose a la hora de configurar senderos de movilidad social ascendente. 
En efecto, las estrategias empresarial/patrimonial y matrimoniales de los padres apoyaron la estrategia educativa para los hijos/as.

En segundo lugar, se creaba un clima propicio para el estudio y ámbitos de autonomía, socializando a los descendientes en una cultura austera, valores rígidos y ansias de superación. Y fomentando la elección de carreras prácticas, con salida laboral (Pérez-Prado, 2007). Coco tuvo un buen desempeño en la universidad; si bien, su trayectoria laboral presentó vaivenes. Tuvo mayores dificultades para insertarse en la profesión, en comparación con los hijos/as de abogados u otros profesionales, quizás porque no contaba con un capital social de origen favorable. No obstante, incursionó en espacios de sociabilidad más abiertos, desarrolló la abogacía, bastante vinculado a la comunidad gallega, y emprendió una sedería familiar con su cuñado de origen judío sefaradí. Coco fue el primero de su generación en titularse en la universidad, tanto de la familia que migró a Buenos Aires como de la que permaneció en Galicia. Aunque su trayectoria no haya significado avances económicos respecto de sus padres, lo fue, sin dudas, en términos de estatus, inaugurando la vía universitaria que continuaron su hijo y sus sobrinos, profesionales, que, en la actualidad, forman parte de las clases medias de mayor estatus de Buenos Aires. No obstante, la estrategia de movilidad social a través de las credenciales educativas no siempre fue exitosa, como veremos a continuación.

Mecanismos de bloqueo a la movilidad social educativa: género, posición en la familia y en el ciclo migratorio

Las biografías familiares señalan que el género, articulado con la posición de los hijos/as en la familia (primogénitos, benjamines, segundogénitos, etcétera) y en el ciclo migratorio (si migran pequeños, en edad más avanzada o si nacen en Argentina), determina una inversión diferencial en educación. Retomemos la historia de Carmen.

Como ya vimos, el abuelo de Carmen emigra solo, abriendo camino. Durante los dos años que está ausente, la hija primogénita (Fernanda) mantiene a la familia que queda en Galicia, apoyada por la segundogénita (Paquita, la madre de Carmen). Las dos van de pueblo en pueblo cosiendo y cuidan de sus hermanos. Aunque para Paquita estudiar era su máxima aspiración, consigue solo acabar sexto grado de primaria. Al llegar a Argentina, se ocupa en el servicio doméstico interno, empujada por sus padres, que no la apoyaron para que prosiguiese los estudios. Esta historia muestra cómo es esencial la posición de los hijos/as en la familia en el momento de la migración. Paquita, al ser una de las hermanas mayores y mujer, tiene que asumir responsabilidades productivas y reproductivas, y ayudar económicamente, con su trabajo, y en los cuidados del hogar, lo cual bloquea su posible ascenso social a través de la educación, mientras que sus hermanas más pequeñas, que emigraron siendo niñas o que nacieron en Argentina, pudieron lograr un nivel de estudios secundarios.

Sin embargo, las hijas de Paquita, Carmen y su hermana, pudieron disfrutar de una movilidad ascendente a través de la educación. Carmen cursaba estudios de historia y era docente en el momento de la entrevista. Su hermana terminó 
la carrera de magisterio y era profesora. De alguna forma, el hecho de que la madre no pudiese estudiar influyó para que fomentase la estrategia de movilidad educativa para sus descendientes. Y hoy en día Paquita está orgullosa de que sus «hijas doctoras» hayan podido alcanzar el sueño que ella vio truncado por ser mujer, así como por su posición en la familia (segundogénita) y en el ciclo migratorio (llegada a Argentina en edad más avanzada).

Por último, las hijas de gallegos, al igual que otras mujeres, de origen migratorio europeo o nativas del AMBA en las décadas de 1960 y 1970, también vieron afectada la trayectoria educativa con la llegada de la maternidad. Esta pauta responde a un modelo de familia de clase media y clase obrera consolidada, según el cual la división de roles en el matrimonio implicaba que el marido fuera el sostén económico del hogar y su fuente de autoridad, y la esposa, la encargada del cuidado del hogar y fuente de afectividad de los hijos/as. Este modelo familiar había cristalizado en las décadas de 1940 y 1950, y aunque se fue resquebrajando, siguió irradiando su influjo en las décadas posteriores, en particular el papel diferencial en la crianza de los hijos/as (Torre, 2010). Este bloqueo de la trayectoria educativa es recurrente en las biografías familiares, sobre todo entre las hijas de migrantes. Es el caso de la madre de Esteban, Ana, así como de la hermana de Coco y de muchas otras mujeres que participaron del estudio. El bloqueo en la trayectoria educativa del matrimonio y la maternidad no está presente entre las nietas de las familias entrevistadas.

\subsubsection{Las redes sociales como soporte de procesos de movilidad ascendente La inversión en capital social también constituyó una estrategia de movilidad social ascendente para las familias de origen gallego, que se plasmó de forma diferente en unos casos y otros. Algunas familias decidieron invertir en capi- tal social coétnico, mientras que otras optaron por alejarse de las redes de la colectividad.}

\section{La apuesta por invertir en capital social gallego}

Como ha resaltado la literatura sobre migraciones, el apoyo en las redes sociales coétnicas constituye un elemento crucial para la inserción laboral en la sociedad de destino y el desarrollo de emprendimientos (Waldinger et al., 1990). Las redes sociales, que servían de puente entre ambos lados del Atlántico, brindaban información sobre oportunidades en Buenos Aires a los que aún no habían tentado la aventura, y a los recién llegados, un techo, comida y contactos para acceder al primer empleo. Significaban también ámbitos de sociabilidad donde recrear la cultura de origen (Germani, 1966; Devoto, 2003; Torre, 2010), y ámbitos propicios para encontrar pareja de origen gallego. Además de los contactos sociales informales, los gallegos, al igual que otros grupos de origen europeo, desarrollaron un densa red de asociaciones mutuales de asistencia social, primero de nivel localista: según provincias o comarcas, pero perduraron las de índole más amplio, sobresaliendo el Centro Gallego de Buenos Aires. Así, para la generación de migrantes, el apostar por capital social gallego favoreció, en los inicios del proceso migratorio, el arraigo en Buenos Aires, y desempeñó 
un papel central en los procesos de movilidad social ascendente, al canalizar los emprendimientos comerciales y apoyar los matrimonios endógamos.

El recurso del capital social coétnico alcanzó igualmente a alguno de los descendientes de la migración. En efecto, algunas familias optaron por socializar a sus hijos/as y nietos/as en la colectividad frecuentando las asociaciones. Es el caso de los hijos/as de Ana. Ambos se acercaron a la cultura gallega a través del baile y la participación en el movimiento asociativo, vínculo que potenció, aún más, la decisión de migrar a Galicia, en un «retorno a las raíces» que, más allá de tener un carácter meramente instrumental, como en otros casos - recuperación de la nacionalidad española con fines de facilitar la migración en contextos de crisis (Golías, 2017)—, estuvo igualmente potenciado por la socialización en la colectividad gallega.

\section{La estrategia de distanciamiento de la colectividad gallega}

Otras familias optaron por salir de las redes coétnicas. Esta estrategia se reproduce, sobre todo, entre los hijos/as de gallegos, y está igualmente presente en el caso de otras colectividades mayoritarias de migrantes (italianos de distintas regiones). La disolución de los lazos y la cultura étnica «...fueron secretamente autorizados en la intimidad de los hogares de los hombres y mujeres que vinieron a hacer la América... con el intento de que sus hijos/as salieran sin hipotecas en busca de las oportunidades que prometía el país» (Torre, 2010: 179). El distanciamiento respecto a la colectividad se llevó a cabo con la idea de que se diese una inserción en ámbitos de sociabilidad más amplios que pudiese permitir una movilidad social de larga distancia. E implicó que las pautas matrimoniales de la segunda generación fueran más abiertas.

La familia de Coco ilustra bien la estrategia de distanciamiento. Aunque Coco y su hermana se criaron en un hogar gallego extenso, que acogía a tíos/ as y primos/as que migraban, tendieron a tomar distancia de los espacios de sociabilidad de la colectividad. La madre no quería que Coco se juntara con los amigos del barrio, por ello los veranos lo mandaba a trabajar a un puesto de venta de frutas y verduras de un tío. Coco contó en su relato que «quería estudiar para dejar de ser como los gallegos brutos de la esquina", que era como llamaban a su familia.

Como vemos, las estrategias de inversión en capital social coétnico o de distanciamiento de las redes de sociabilidad gallegas están articuladas con el resto de estrategias. En el caso de la primera generación, los fuertes lazos de solidaridad entre la comunidad gallega fueron clave a la hora de llevar a cabo procesos de movilidad social ascendente, favoreciendo la vía empresarial, a su vez, apoyada por el matrimonio endogámico. Entre la segunda generación, algunos hijos/as combinaron la apuesta por la movilidad social educativa, con el distanciamiento de la comunidad gallega. Por último, la socialización en el ámbito de la colectividad también sirvió de sustento, junto a la nacionalidad, para algunos nietos/as de migrante que optan por migrar a Galicia. Pasamos a profundizar en esta última estrategia de ascenso social: el «retorno a las raíces». 


\subsubsection{El «retorno a las raíces» de descendientes de gallegos}

La llegada de la crisis de 2001 suscitó para muchas familias de gallegos un «retorno a las raíces», en la medida en que muchos descendientes de migrantes aprovecharon algunos recursos, como la nacionalidad española, redes de contacto que les proporcionaba ser hijos/as o nietos/as de la migración, para hacer las maletas y emprender rumbo a España (Golías, 2017; Oso et al., 2008). Atraídos por el boom económico que se desarrolló en España a principios de siglo, muchos descendientes de gallegos aprovecharon las oportunidades que brindaba la demanda de mano de obra no cualificada, sobre todo en el sector de la construcción y de servicios personales. Además de ubicarse en estos yacimientos de empleo, que el mercado de trabajo español reservó para la población inmigrante, los llegados de Argentina destacaron en Galicia por la puesta en marcha de emprendimientos, impulsados por la mentalidad empresarial que habían heredado de sus progenitores (Oso et al., 2007).

$\mathrm{El}$ «retorno a las raíces» fue una estrategia puesta en marcha por algunos de los descendientes de gallegos, tales como los hijos/as de Ana y los primos de Carmen. Los hijos/as de Ana estudiaron en la universidad, uno la carrera de dirección de cine y otra grafología, de manera que la familia avanza un escalón más en el plano de la movilidad social educativa. En el caso de Ana, el estar en contacto con la colectividad gallega (directora de un cuerpo de baile gallego) ha supuesto un recurso adicional, además del acceso a la nacionalidad y las redes de contacto, que ha servido a los hijos/as (que también bailan folclore gallego) para ganar un vínculo emocional y cultural con Galicia, que ha sido determinante para impulsar el nuevo proceso migratorio de los jóvenes. No obstante, a pesar de sus estudios universitarios, los hijos/as de Ana ocupan puestos de trabajo no acordes a su cualificación, y trabajan en Galicia como empleados no cualificados (empresa de seguridad y cajera de supermercado), lo que les lleva a un desclasamiento, en sintonía con lo vivido por muchos compatriotas argentinos que migraron a España tras la crisis de 2001 (Jiménez Zunino, 2011).

Por último, en la familia de Carmen también encontramos presente la estrategia de basada en el «retorno a las raíces»; si bien se trata de una migración de carácter más instrumental y con menos «atracción emocional», en comparación con los hijos de Ana. En efecto, tres de los primos de Carmen, que no estuvieron socializados en las redes de la comunidad, pero aprovechando igualmente los recursos que el origen español les proporciona (nacionalidad), deciden migrar a España tras la crisis de 2001. Y en este caso, no lo hacen a Galicia, sino a Palma de Mallorca, puesto que tienen menos arraigado el vínculo emocional con el país de origen de sus abuelos. Les va bien, pero no salen del trabajo poco cualificado y, al llegar la crisis económica española de 2008, los más pequeños se ven obligados a regresar a Argentina para insertarse igualmente en empleos menos cualificados.

\subsection{Trayectorias familiares de clase}

Pasamos a describir en qué medida las estrategias de movilidad social puestas en marcha por las familias entrevistadas, influidas por los proyectos migratorios 
y articuladas con la estructura de oportunidades, van configurando las trayectorias intergeneracionales (abuelos, hijos/as y nietos/as) de clase: ascendentes, descendentes o de reproducción social.

\subsubsection{Movilidad social ascendente de larga distancia y arraigo en Buenos Aires}

La historia de familia de Coco representa un tipo de trayectoria típica de movilidad social ascendente a través de tres generaciones ${ }^{7}$ de familias de origen gallego en Buenos Aires que arribaron dos décadas antes (que las otras tres familias estudiadas) en un contexto de expansión de mayores oportunidades. En esta trayectoria familiar se advierte, en términos de Bourdieu (2011), una reconversión relativamente exitosa de capital económico hacia el capital cultural. La tercera generación cuenta en sus espaldas con la acumulación económica desarrollada sobre todo en la primera generación y mayor capital cultural otorgado por la segunda para insertarse con mayor éxito en su ámbito de desempeño profesional. Se trata de una familia plenamente arraigada en Buenos Aires, distanciada de las redes de la colectividad gallega, para la cual la combinación de capitales le permitió sortear las crisis económicas de Argentina del último cuarto del siglo XX y continuar luego su camino de ascenso en un contexto de expansión económica.

\subsubsection{Movilidad social ascendente de corta distancia, estancamiento y retorno a las raices}

En la familia de Ana, la estrategia de movilidad social centrada en el emprendimiento y la acumulación de bienes patrimoniales, en el marco de una estructura de oportunidades favorable (sociedad abierta de los años cincuenta), permitió una movilidad social ascendente de corta distancia para la primera generación (abuelos). La estrategia de inversión en educación universitaria para la segunda generación se ve truncada, en el caso de Ana, por la llegada temprana del matrimonio y la maternidad. La crisis económica de 2001 impacta en la trayectoria de movilidad social de la familia, y lleva finalmente a la segunda generación a reproducir las ocupaciones que desarrollaron sus padres (pequeños empresarios). El capital patrimonial que hicieron los gallegos de la primera generación a través de pequeños comercios ha permitido amortiguar los efectos de la crisis económica para los hijos/as, ya que les ha brindado posibilidades para salir de la recesión a través del emprendimiento (ayuda para la inversión inicial y socialización en el trabajo por cuenta propia). Por su parte, los nietos/as, que no ven revalorizados sus títulos universitarios en el contexto social argentino poscrisis y atraídos por el vínculo emocional con Galicia (socializados en la colectividad) optan por «el retorno a las raíces», lo cual les lleva a reproducir ocupaciones no cualificadas, como hicieron sus abuelos al llegar a Buenos Aires.

7. En este apartado nos referimos a este término para hacer alusión a las diferentes generaciones familiares. 


\subsubsection{Movilidad social ascendente y reproducción en las clases medias a través de la vía de la pequeña empresa familiar, sin una "nueva migración"}

En la familia de Esteban se da una movilidad ascendente intrageneracional del abuelo materno, pero de corto alcance, de carpintero asalariado a pequeño empresario dueño de una carpintería. Por su parte, se constata una movilidad ascendente para el padre, quien gracias a la herencia que recibe del tío entra en la cadena de los negocios de gallegos y consigue una buena posición empresarial (garaje, otras inversiones). No obstante, la madre ve frenada su movilidad social educativa por el matrimonio. En el caso de Esteban y su hermano (hijos/as y nietos/as de migrantes), constatamos una movilidad social intergeneracional en lo relativo a la trayectoria educativa (los dos estudian en la universidad, uno administración de empresas, el otro música). Si bien en el momento de la entrevista se constataba un estancamiento en la movilidad laboral: ahora gestionan un bar, por lo que son pequeños empresarios, reproduciendo así la ocupación del padre. Gracias a la herencia de la "cultura empresarial», pueden hacer frente a las dificultades de revalorizar su título universitario.

\subsubsection{Reproducción en la clase obrera urbana y ascenso social con arraigo}

En cuanto a la familia de Carmen, observamos la permanencia en la clase obrera urbana para la primera y segunda generación, ya que no logran salir de trabajos manuales asalariados. El género y la posición en la familia y en el ciclo migratorio de Paquita, la madre, limitan sus posibilidades de ascenso social vía educación al llegar a Argentina; su matrimonio, con un obrero de su misma condición social, tampoco ayuda en su camino de ascenso social. Sí mejora su situación económica gracias a la herencia de su hermana Fernanda, que sigue la estrategia de los empresarios gallegos. La movilidad intergeneracional ascendente, para esta familia, está sobre todo protagonizada por las nietas de la migración, Carmen y su hermana, que consiguen diplomas universitarios y una posición en el mercado de trabajo acorde a su nivel de estudios, y a quienes «no se les pasa por la cabeza la idea de migrar». Sí lo hacen sus primos, pero más por una razón instrumental (disposición de la nacionalidad española) que de vínculo emocional, a diferencia de los hijos de Ana.

\section{Conclusiones}

En este estudio articulamos el análisis de pautas y estrategias de movilidad social intergeneracional de familias migrantes gallegas pertenecientes a la última corriente migratoria que arribó a Argentina entre 1940 y 1960.

El análisis cuantitativo mostró altas tasas de movilidad ascendente de corta distancia de la primera generación. Los migrantes gallegos pasan de ser labradores/as a obreros/as en Buenos Aires: los hombres se insertan principalmente en el sector de servicios como mozos o lavacopas en restaurantes, lecheros, entre otros, aunque también en frigoríficos y otras industrias; las mujeres, como empleadas domésticas u obreras textiles. Después de un período de asentamien- 
to, una proporción considerable de los migrantes experimenta una movilidad intrageneracional ascendente, de obreros/as a pequeños/as comerciantes.

Respecto a hijos/as de migrantes gallegos de la corriente de posguerra, constatamos una inserción en el estrato inferior de clases medias, siguiendo los comercios de sus progenitores o a través de empleos técnicos o administrativos. De manera similar a otros grupos de origen europeo, tuvieron altas tasas de acceso al estrato superior de clases medias a través de la obtención de títulos universitarios, aunque levemente inferiores, en comparación con los hijos/as de migrantes de la primera corriente migratoria (1857 y 1936).

En cuanto a los nietos/as de migrantes gallegos, se insertan en la clase media directiva/profesional en una proporción similar a otros grupos de origen europeo y en mayor medida que el promedio, y adquieren credenciales de títulos universitarios. Una proporción considerable parte del estrato inferior de clases medias: sus padres eran comerciantes, técnicos o empleados, lo cual da cuenta de la continuidad de procesos de movilidad social ascendente de las familias de origen gallego en Buenos Aires.

No obstante, el análisis cuantitativo no muestra cuáles fueron los principales determinantes que, en un contexto de migración internacional, indujeron a los gallegos y sus descendientes a desarrollar estas pautas de movilidad social. Tampoco saca a la luz la complejidad de las trayectorias de clase y estrategias de movilidad social, marcadas por las diferencias de género y el contexto de oportunidades. El análisis cualitativo permite visibilizar, más allá de la inversión en educación, otras dimensiones en las trayectorias de movilidad social: las estrategias empresariales y patrimoniales, incluyendo las herencias; las estrategias matrimoniales; la fuerza de los vínculos con el capital social coétnico, y las estrategias de movilidad espacial (tránsitos de ida y vuelta en el espacio transnacional).

Las biografías familiares han puesto de manifiesto que la estrategia más óptima de ascenso de los migrantes gallegos de posguerra fue desarrollar emprendimientos con socios paisanos (restaurantes, almacenes, panaderías y hoteles), siguiendo el camino que iniciaron sus predecesores de la primera corriente migratoria e impulsados por ellos. Aunque los gallegos de posguerra llegan a Buenos Aires en el contexto de una estructura de clases más consolidada y más cerrada al ascenso social vía propiedad de capital, el apoyo de las densas redes sociales y empresariales que disponía la colectividad, tejidas y consolidadas a través de las diferentes corrientes migratorias, ayuda a que consigan abrirse camino, a través del emprendimiento, en un contexto menos favorable.

Esta estrategia empresarial fue igualmente favorecida por el proyecto migratorio. Los migrantes gallegos de posguerra en Buenos Aires, a diferencia de los que marcharon a Europa en los años 60-70 (proyecto migratorio de ahorro, retorno e inversión en Galicia), buscaron un mayor asentamiento en el contexto de acogida y centraron su estrategia de movilidad social en invertir las ganancias en Argentina.

La estrategia empresarial se fundamentó igualmente en la conformación de matrimonios endogámicos de clase obrera que encaran un proyecto de ascenso 
social juntos llevando una vida austera y frugal, en el que es central el rol de las mujeres, que combinaron las labores reproductivas en el hogar con el trabajo en los comercios familiares. Tal y como han puesto de manifiesto igualmente otros estudios (Nuñez Seixas y Farías, 2012: 70), este trabajo muestra que en las familias gallegas se da una transmisión intergeneracional de valores vinculados al «trabajo duro" y el «ahorro», que en la primera generación de migrantes se materializa en la compra de propiedades, alquiladas, con frecuencia, para incrementar los ingresos. La continuidad de los emprendimientos comerciales familiares permitió a los descendientes de gallegos amortiguar épocas de crisis, y las herencias fueron un trampolín para la movilidad social. En la generación de los hijos/as y nietos/as la herencia fue un recurso importante de transmisión intergeneracional, que favoreció el acceso a las clases medias de mayor estatus socioeconómico.

El logro educativo de los descendientes de gallegos se apoyó en el esfuerzo y la articulación de estrategias de la generación migrante: el progreso económico brindó una base de bienestar para desarrollar estudios secundarios o una carrera universitaria, y la socialización en una cultura austera con ansias de superación potenció la captación de oportunidades en un contexto dinámico. Sin embargo, los diplomas educativos no siempre se correspondieron con un logro ocupacional, constatándose tres «mecanismos de bloqueo» a la movilidad educativa: la desigualdad de género, la posición en la familia y el momento de la migración en el ciclo vital. Los hijos/as mayores que migraron con sus familias de origen, o reagrupados posteriormente, tuvieron menores oportunidades de proseguir trayectorias educativas largas. En particular, el papel de hijas mayores en el cuidado y crianza de los hermanos/as dificulta las posibilidades de estudiar. Entre las hijas de familias gallegas que nacieron en Buenos Aires la culminación de la escuela secundaria fue amplia; sin embargo, la llegada de la maternidad frenó las posibilidades de finalizar carreras universitarias. Por último, hemos encontrado que, en la generación de los nietos/as, el matrimonio y la llegada de los hijos/as no truncan la trayectoria educativa, sino que contrariamente estos eventos vitales significativos se retrasan en pos de alcanzar la titulación.

En general, los hijos/as de migrantes gallegos tendieron a tomar distancia de los espacios de sociabilidad de la colectividad con la idea de incursionar en ámbitos más amplios, siendo mayor el distanciamiento de las redes sociales de la migración en la generación de los nietos/as. Sin embargo, para algunas familias, la socialización en el ámbito de la colectividad siguió manteniéndose, y sirvió de sustento, incluso, para un «retorno a las raíces» de carácter más emocional y menos instrumental que en otros casos.

En el marco del estancamiento económico de Argentina, en el último cuarto del siglo XX, y sobre todo en el contexto de la crisis 2001-2002, los descendientes de familias gallegas que no lograron reconvertir el capital económico en capital cultural de nivel alto experimentan cierto descenso. Algunos hijos/as y nietos/as de migrantes retornaron a Galicia en búsqueda de mejores oportunidades. Sin embargo, en España ven truncados sus sueños de movilidad social 
ascendente: al llegar a una estructura social bastante cristalizada se insertan en ocupaciones no cualificadas (Jiménez Zunino, 2011), por debajo de su nivel de estudios, y vuelven a posiciones que vivieron sus abuelos/as en el inicio del ciclo migratorio.

En suma, las trayectorias de clase analizadas nos muestran que entre las familias de origen gallego en Buenos Aires predomina la movilidad social ascendente que se fue haciendo más "escalonada" y con mayores vaivenes, a medida que la sociedad argentina fue perdiendo dinamismo económico. En ese marco, las trayectorias de clase no siempre fueron lineales en sentido ascendente.

A diferencia de los trabajos sobre movilidad social de corte cuantitativo, este artículo ha puesto de relieve que las biografías familiares son complejas, de tal manera que dentro de la misma familia encontramos trayectorias de movilidad social que siguen pautas divergentes: podemos constatar una movilidad social ascendente para la primera generación, pero una reproducción para la segunda e incluso un descenso de clase para la tercera. Se puede ascender socialmente, en términos de credenciales educativas, pero estancarse económicamente por no poder revalorizarlas en el mercado de trabajo. Además, los senderos de clase no se reproducen de la misma manera para unos y otros dentro de las familias, lo cual se pone claramente de manifiesto cuando incluimos el enfoque de género.

El estudio también ha sacado a la luz que las diferentes estrategias de movilidad social no se presentan de forma aislada, sino que se articulan entre sí. La estrategia empresarial y patrimonial se apoyó en el matrimonio endogámico y, a su vez, sustentó la estrategia educativa de los hijos/as. La inversión en capital coétnico potenció, por su parte, los emprendimientos, mientras que el distanciamiento respecto a la comunidad supuso una forma de apertura a otras redes sociales que, junto a la educación, favoreció el matrimonio exogámico, como vía de ascenso social.

Por otro lado, el trabajo muestra que se han ido articulando las estrategias productivas y reproductivas en las trayectorias de clase, y que el enfoque de género contribuye a comprender las pautas de movilidad social. Sin el trabajo de las mujeres en los negocios familiares, sin el freno de las trayectorias educativas de alguna de ellas, que sacrificaron los estudios para dedicarse a los cuidados, no podemos entender las pautas familiares de movilidad social.

En definitiva, este artículo ha pretendido contribuir a la literatura sobre migración gallega a Argentina con una mirada sociológica, centrada en el estudio de la movilidad social intra e intergeneracional de la corriente migratoria de posguerra, sobre la base de un estudio, cuantitativo y cualitativo, basado en un enfoque que analiza la relación entre la movilidad espacial y social. Hemos intentado dar cuenta de que, más allá del recurso de la educación, existe un entramado complejo de estrategias articuladas, influidas por un proyecto migratorio de asentamiento, que contribuye a comprender las trayectorias de clase de las familias de origen gallego en Buenos Aires: procesos de movilidad social ascendente de larga y corta distancia escalonados, basados en el encadenamiento de esfuerzos y acumulación de recursos entre generaciones. 


\section{Referencias bibliográficas}

Bertaux, Daniel y Thompson, Paul (1997). Pathways to social class. A qualitative approach to social mobility. Oxford: Clarendon Press.

BERTRAND, Jean-René (1999). «La emigración gallega, ¿sistema original?». SEMATA, Ciencias Sociais e Humanidades, 11, 439-455. <https://minerva.usc.es/xmlui/handle/10347/4673>.

Bourdieu, Pierre (2011). Las estrategias de la reproducción social. Buenos Aires: Siglo XXI.

BOURDIEU, Pierre y WACQUANT, Loic (1986). Respuestas para una antropología reflexiva. México DF: Grijalbo.

Cagiao Vila, Pilar (1997). Muller e emigración. Santiago de Compostela: Xunta de Galicia.

CASSAIN, Laura (2018). Volver. Trayectorias migratórias y processos de retorno de España a Argentina. Tesis doctoral dirigida por Elena Casado y Lorenzo Cachón. Universidad Complutense de Madrid.

CHISWICK, Barry; YEW, Lee y Miller, Paul (2005). «A longitudinal analysis of immigrant occupational mobility: A test of the immigrant assimilation hypothesis». International Migration Review, 39 (2), 332-353. <https://doi.org/10.1111/j.1747-7379.2005.tb00269.x>.

CRISTÓFORIS, Nadia de (2007). "Argentina como destino de la emigración gallega luego de la Segunda Guerra Mundial». En Farías, Ruy (comp.). Buenos Aires gallega. Inmigración, pasado y presente. Buenos Aires: Comisión para la Preservación del Patrimonio Cultural de la Ciudad Autónoma de Buenos Aires.

Cristóforis, Nadia de (2010). Bajo la Cruz del Sur: Gallegos y asturianos en Buenos Aires (1820-1870). La Coruña: Fundación Pedro Barrié de la Maza.

CuIN, Charles Henry (1993). Les sociologues et la mobilité sociale. París: PUF.

DALLE, Pablo (2013). «Movilidad social ascendente de familias migrantes de origen de clase popular en el Gran Buenos Aires». Trabajo y Sociedad, 21, 373, 401. <http://hdl.handle.net/11336/15713>.

- (2016). Movilidad social desde las clases populares. Un estudio sociológico en el Area Metropolitana de Buenos Aires (1960-2013). Buenos Aires: CLACSO/ Instituto de Investigaciones Gino Germani-UBA / CICCUS.

Devoto, Fernando (2003). Historia de la inmigración en la Argentina. Buenos Aires: Sudamericana.

FARÍAS, Ruy (2012). «Revisitando la conducta matrimonial de los inmigrantes: el caso de los españoles en el Partido de Barracas al Sud / Avellaneda (1890-1930)». En: Cancino, Hugo; Mora, V. Rogelio de la; Medeiros de Menezes, Lenà y Benito Moya, Silvano G. A. (eds.). Miradas desde la Historia social y la Historia intelectual. América Latina en sus culturas: de los procesos independentistas a la globalización. Córdoba: Centro de Estudios Históricos Prof. Carlos S. A. Segreti / Universidad Católica de Córdoba / Universidad Veracruzana, 225-49.

<http://www.ucc.edu.ar/portalucc/archivos/File/Filosofia/2013/libro-virtualMiradas-completo.pdf $>$.

- (2016). «Migraciones y exilios gallegos en la Argentina (siglos XVIII-XXI): algunos comentarios a la bibliografía sobre el tema». En: Lojo, M. R. (ed.). Galicia en la Argentina: una identidad transatlántica. Olivar, 17 (25), e008.

<https://www.olivar.fahce.unlp.edu.ar/article/view/OLIe008>.

Germani, Gino (1963). «La movilidad social en Argentina». En: LIPSET, S. y BENDIX, R. (eds.). Movilidad social en la sociedad industrial. Buenos Aires: EUDEBA. 
- (1966). Politica y sociedad en una época de transición Buenos Aires: Paidós.

Golías PÉREZ, Montserrat (2017). Los herederos de la ciudadanía. Nuevos españoles a través de la ley de la memoria histórica en Cuba y Argentina. Madrid: Icaria Editorial.

JimÉNEZ Zunino, C. (2011). Desclasamiento y reconversiones en las trayectorias de los migrantes argentinos de clases medias. Tesis doctoral, Universidad Complutense de Madrid. <https://www.tdx.cat/handle/10803/517214>.

LAÍz MOREIRA, Sofía (2014). Moviendo ficha: jóvenes migrantes, estrategias y trayectorias familiares de movilidad social intergeneracional en las migraciones argentinas y marroquies a Galicia. Tesis doctoral dirigida por Laura Oso y Natalia Ribas-Matéos, Universidade da Coruña.

<http://ruc.udc.es/dspace/bitstream/handle/2183/14186/LaizMoreira_Sofia_ TD_2014.pdf?sequence $=4>$.

Lojo, María Rosa; GuidotTi de SÁnChez, M. y Farías, Ruy (2008). Los 'gallegos'en el imaginario argentino. Literatura, sainete, prensa. La Coruña / Vigo: Fundación Pedro Barrié de la Maza.

Moya, José C. (2004). Primos y extranjeros. La inmigración española en Buenos Aires. 1850-1930. Buenos Aires: Emecé.

Núñez SeiXAS, Xosé Manoel (2007). "Galicia e Arxentina, Galicia na Arxentina». En: Cagiao Vila, Pilar y Núñez SeiXas, Xosé Manoel. Os galegos de ultramar. II. Galicia e o Río da Prata, 11-152. La Coruña: Arrecife Edicións Galegas,

NúÑEZ SEIXAS, Xosé Manuel y Farías, Ruy (2010). «Las autobiografías de los inmigrantes gallegos en la Argentina (1860-2000): testimonio, ficción y experiencia». Migraciones y Exilios (11), 57-80.

$<$ https://dialnet.unirioja.es/descarga/articulo/3616978.pdf>.

ORDEN, María Liliana da (2005). Inmigración española, familia y movilidad social en la Argentina moderna. Una mirada desde Mar del Plata (1890-1930). Buenos Aires: Biblos.

Oso, Laura (2004). Españolas en París. Estrategias de ahorro y consumo en las migraciones internacionales. Barcelona: Bellaterra.

- (dir. 2015-2019). Género, movilidades cruzadas y dinámicas transnacionales. Proyecto financiado por el Ministerio de Economía y Competitividad (FEM2015-67164-R).

Oso Casas, Laura; Golías Pérez, M. y Villares Varela, M. (2008). «Inmigrantes extranjeros y retornados en Galicia: la construcción del puente transnacional». Politica y Sociedad, 45 (1). <http://revistas.ucm.es/index.php/POSO/article/view/23265>.

- (2007). Los colectivos migrantes ante el proceso de emprendimiento en Galicia. La Coruña: Servizo de Publicacións, Universidade da Coruña.

$<$ http://emigracion.xunta.gal/es/conociendo-galicia/aprende/publicacion/colectivos-migrantes-ante-proceso-emprendimiento-galicia>.

Oso, Laura y SuÁREZ-GRIMALT, L. (2017). «Towards a theoretical model for the study of productive and reproductive strategies in transnational families: Latin American migration and social mobility in Spain». Journal of Family Studies. $<$ https://doi.org/10.1080/13229400.2017.1374202>.

Oso, Laura; SÁiz-López, A. y CORTÉS A. (2017). «Presentación del monográfico. Movilidades cruzadas en un contexto de crisis: Una propuesta teórica para el estudio de la movilidad geográfica y social, con un enfoque de género, transnacional e intergeneracional». Revista Española de Sociología, 26 (3), septiembre. $<$ https://doi.org/10.22325/fes/res.2017.24>. 
Pérez-Prado, Antonio (2007 [1973]). Los gallegos y Buenos Aires. Buenos Aires: Corregidor.

SouTElo VÁzQUEZ, Raúl (2006). «Proyectos migratorios, itinerarios laborales y redes microsociales de los emigrantes en su correspondencia familiar dos gallegos en Buenos Aires (1950-1966)». Migraciones \& Exilios: Cuadernos de la Asociación para el estudio de los exilios y migraciones ibéricos contemporáneos (ejemplar dedicado a Alemania, país de acogida de la emigración española), 115-136.

TORRE, Juan Carlos (2010). "Transformaciones de la sociedad argentina». En: Russel, R. (ed.). Argentina 1910-2010. Balance del siglo. Buenos Aires: Taurus.

VÁZQUEZ GONZÁLEZ, Alexandre (2011). «Algunhas precisións cuantitativas sobre la última vaga emigratoria galego-arxentina». En: CRISTÓFORIS, Nadia de (coord.). Baixo o signo do franquismo: emigrantes e exiliados galegos na Arxentina, ("Diáspora»). $1^{a}$ edición, 31-57. Santiago de Compostela: Sotelo Blanco Edicións.

Villares, Ramón y FERnÁndeZ, Marcelino (1996). Historia da emigración galega a América. Santiago de Compostela: Xunta de Galicia.

WALDINGER, R.; Aldrich, H. y WARD, R. (1990). «Opportunities, group characteristics and strategies». En: WALDINGER, R. et al. Ethnic entrepreneurs. Immigrant business in industrial societies, 13-48. Londres: Sage Publications. 
